\title{
Sistem Informasi Kinerja Layanan Laboratorium Medis dengan Metode Six Sigma
}

\author{
Anindita Kusuma Dewi ${ }^{\mathrm{a}^{*}}$, Ibnu Widiyanto ${ }^{\mathrm{b}}$ \\ ${ }^{\text {a, }}$ Mahasiswa Magister Sistem Informasi Universitas Diponegoro \\ ${ }^{\mathrm{b}}$ Magister Manajemen, Fakultas Ekonomika dan Bisnis, Universitas Diponegoro
}

Naskah Diterima : 10 Juni 2015; Diterima Publikasi : 30 Juli 2015

\begin{abstract}
Medical Laboratory currently holds a very important role in medicine. Evaluation of laboratory quality plays a very important to maintain accurate laboratory results. This study aims to design an information system performance based on the same perception of medical laboratory services from customers using Six Sigma methods and frameworks using ServQual questionnaire. Selection of Six Sigma itself is based on this method can measure the extent to which each process deviates from its purpose as well as to reduce the variation of each of the attributes. Six Sigma DMAIC namely (Define, Measure, Analyze, Improve, Control) preferred because the end result will not yield new products, but only improvements on existing processes. The results of this calculation will be presented in the form of a dashboard for easier management in understanding the results of the evaluation. From the system can be obtained an average value of consumer perceptions terhdap performance today is 2,883 , consumer expectations on the performance of 3.3768 , the gap between the perceptions and expectations of consumers is -0.4936 , customer satisfaction will be the performance of the current $85.37 \%$, the value of 423360 DPMO and sigma value there at the 2.07664 level.
\end{abstract}

Keywords: Laboratory Performance; Six Sigma; Servqual; Dashboard

\begin{abstract}
Abstrak
Laboratorium medis saat ini memegang peran yang sangat penting dalam dunia kedokteran. Eevaluasi kinerja laboratorium memegang peranan yang sangat penting untuk mempertahankan hasil laboratorium yang akurat serta pelayanan yang baik. Penelitian ini bertujuan untuk merancang suatu sistem informasi kinerja layanan laboratorium medis berdasarkan pesepsi dari pelanggan menggunakan metode Six Sigma dan kerangka kuesioner menggunakan ServQual. Pemilihan Six Sigma sendiri berdasarkan pada metode ini dapat mengukur sejauh mana setiap proses menyimpang dari tujuannya serta dapat mengurangi variasi dari tiap atribut yang ada. Metode Six Sigma yang dipilih yaitu DMAIC (Define, Measure, Analyze, Improve, Control) hal ini karena pada hasil akhir tidak akan menghasilkan produk baru, tetapi hanya perbaikan pada proses yang ada. Hasil dari perhitungan ini akan disajikan dalam bentuk dashboard untuk lebih memudahkan pihak manajemen dalam memahami hasil evaluasi. Dari sistem diperoleh nilai rata-rata dari persepsi konsumen terhdap kinerja saat ini yaitu 2.883, harapan konsumen terhadap kinerja 3.3768, gap antara persepsi dan harapan konsumen yaitu -0.4936 , kepuasan pelanggan akan kinerja saat ini 85.37\%, nilai DPMO 423360, dan nilai sigma ada pada tingkat 2.07664.
\end{abstract}

Kata kunci: Kinerja Laboratorium; Six Sigma; Servqual; Dashboard

\section{Pendahuluan}

Keberadaaan laboratorium medis saat ini memegang peranan yang sangat penting. Hal ini tidak lepas dari ketergantungan dokter dalam mengambil keputusan berdasarkan hasil pemeriksaan yang dilakukan oleh laboratorium. Dalam konteks ini, hasil tes yang akurat sangat penting bagi dokter dan pasien mereka. Hal yang terpenting adalah laboratorium harus mampu menghasilkan hasil tes yang akurat sebelum dimensi lain dari kualitas menjadi penting. Dari sudut pandang ini, evaluasi kinerja laboratorium sangat penting untuk mempertahankan hasil laboratorium yang akurat (Coskun et al., 2010).

Di Indonesia, sekarang ini inisiatif untuk jaminan kualitas dan peningkatan kualitas di laboratorium terutama didorong oleh persyaratan dari lembaga regulator dan akreditasi negara. Sebagai respon dari akreditasi ini maka laboratorium harus mengidentifikasi indikator yang akan digunakan untuk mengukur kinerja yang berhubungan dengan pelayanan dan kepuasan pasien (Nevalainen et al., 2000).

*) Penulis korespondensi: anindita.kusumadewi@gmail.com 
Tujuan dari pengukuran ini yaitu meningkatkan kinerja laboratorium dengan cara merancang agar proses yang ada menjadi lebih baik dan secara sistematis mengukur, menilai dan meningkatkan kinerja saat ini. Penelitian ini mengambil kasus pada instalasi laboratorium RSUD Tuguredjo Semarang.

Instalasi Laboratorium klinik RSUD Tuguredjo Semarang sesuai dengan Permenkes no. 129/Menkes/SK/2008 maka memiliki standar pelayanan minimum sebagai berikut waktu tunggu hasil pelayanan laboratorium sebesar $91.83 \%$ ( waktu rata-rata untuk pemeriksaan hemotologi 78 menit dan kimia klinik 84.4 menit) dengan waktu pencapaian 2 tahun, pelaksanaan ekspertisi oleh dokter spesialis patologi klinik dengan waktu pencapaian 1 tahun, tidak adanya kesalahan pemberian hasil pemeriksaan laboratorium mencapai $100 \%$ dengan batas pencapaian 5 tahun, sedangkan untuk survey kepuasan pelanggan mengikuti survey yang dilakukan oleh Rumah Sakit dengan batas pencapaian 5 tahun. Selain itu kelengkapan data permintaan laboratorium pada fase pre analitik antara lain : untuk kelengkapan data nama pasien $100 \%$, kelengkapan data umur/jenis kelamin $84 \%$, kelengkapan data no rekam medis $81.5 \%$, kelengkapan data ruang $80 \%$, kelengkapan data penerimaan sampel $100 \%$, kelengkapan data dokter pengirim $87.5 \%$, kelengkapan diagnosa $56 \%$.

Untuk melakukan pengukuran standar pelayanan minimum laboratorium dipilih metode Six Sigma. Alasan pemilihan metode ini yaitu Strategi six sigma mengukur sejauh mana setiap proses menyimpang dari tujuannya. Nilai sigma menunjukkan seberapa sering cacat yang mungkin terjadi. Alasan lain pemilihan metode ini adalah karena Six Sigma melibatkan suatu usaha terus menerus untuk mengurangi variasi proses ke minimum, sehingga proses secara konsisten memenuhi harapan dan persyaratan pelanggan (Pyzdek,2001).

Tujuan dari penelitian ini yaitu membangun sistem informasi kinerja layanan laboratorium dengan menggunakan metode Six Sigma dengan bantuan kuesioner Servqual.

\section{Kerangka Teori}

\subsection{Pengertian Kinerja}

Menurut Herfert (1996) kinerja adalah suatu tampilan keadaan secara utuh atas perusahaan selama periode waktu tertentu, merupakan hasil atau prestasi yang dipengaruhi oleh kegiatan operasional perusahaan dalam memanfaatkan sumber-sumber daya yang dimiliki.

Pendapat yang lain menyatakan bahwa kinerja adalah hasil atau tingkat keberhasilan seseorang secara keseluruhan selama periode tertentu di dalam melaksanakan tugas dibandingkan dengan berbagai kemungkinan, seperti standar hasil kerja, target atau sasaran atau kriteria yang telah ditentukan terlebih dahulu dan telah disepakati bersama (Rivai dan Fawzi, 2005).

\subsection{Six Sigma}

Six Sigma merupakan suatu metode atau teknik pengendalian dan peningkatan kualitas secara dramatis yang merupakan terobosan dalam bidang kualitas.

Harry dan Schroeder (2000) dalam Coskun (2010) mendefinisikan Six Sigma sebagai proses bisnis yang memungkinkan perusahaan untuk secara drastis meningkatkan bottom line mereka dengan merancang dan memantau kegiatan bisnis sehari-hari dengan cara meminimalkan limbah dan sumber daya sementara di satu sisi meningkatkan kepuasan pelanggan.

Menurut Davig et al. (2003) dalam Raisinghani et al. (2005) sebagai metodologi pengukuran kualitas, Six Sigma juga sedang diadopsi oleh beberapa industri jasa untuk meningkatkan proses mereka untuk menghasilkan kepuasan pelanggan berkualitas.

Tujuan Six Sigma adalah untuk mengurangi jumlah pengalaman pelanggan buruk untuk tiga dalam satu juta (untuk tingkat Six-Sigma). Metodologi Six Sigma digunakan untuk mendapatkan informasi faktual mengenai kepuasan pelanggan. Untuk lebih jelasnya dapat dilihat dalam Tabel 1. Dari gambar tersebut terlihat bahwa pada tingkatan sigma yang paling tinggi (6) hanya terdapat 3.4 DPMO per 1.000.000.

Tabel 1. Jumlah cacat per juta

\begin{tabular}{ccc}
\hline $\begin{array}{c}\text { Probabilitas } \\
\text { Tanpa Cacat }\end{array}$ & $\begin{array}{c}\text { Defect Per Million } \\
\text { Opportunities (DPMO) }\end{array}$ & $\begin{array}{c}\text { Level } \\
\text { Sigma }\end{array}$ \\
\hline 30.9 & 690000 & 1 \\
69,2 & 308000 & 2 \\
93,3 & 66800 & 3 \\
99,4 & 6210 & 4 \\
99,98 & 320 & 5 \\
99,9997 & 3,4 & 6
\end{tabular}

\subsection{Metodologi Six Sigma}

Berbagai upaya untuk mencapai target Six Sigma dapat dilakukan dengan dua metodologi yaitu Six Sigma - DMAIC ( Define Measure Analyze Control), dan Design for Six Sigma - DFSS DMADV (Define Measure Analyze Design Verify). Perbedaan keduanya terletak pada DMAIC digunakan untuk meningkatkan proses bisnis yang telah ada sedangkan DMADV digunakan untuk menciptakan desain proses baru dan/atau desain produk baru agar menghasilkan kinerja bebas kesalahan (Gasperz dan Vontana, 2011).

Penelitian ini akan menggunakan Six Sigma DMAIC karena tidak bertujuan untuk menciptakan suatu desain proses atau produk baru, oleh karena itu pembahasan yang ada akan lebih ditekankan pada metodologi ini. Metodologi Six Sigma DMAIC terdiri dari 5 tahap utama yaitu : 


\section{Tahap Define}

Mendefinisikan secara formal sasaran peningkatan proses yang konsisten dengan permintaan atau kebutuhan pelanggan dan strategi perusahaan. Tahap ini bertujuan untuk menetapkan hasil yang diinginkan, mengidentifikasi stakeholder, mengidentifikasi produk atau proses yang perlu diperbaiki, mengidentifikasi kesempatan atau prioritas.

\section{Tahap Measure}

Tahap measure bertujuan untuk mengukur kinerja pada saat ini (baseline measurement) agar dapat dibandingkan dengan target yang ditetapkan. Pada tahap ini dilakukan pemetaan proses dan pengumpulan data yang berkaitan dengan indikator kinerja kunci (Key Performance Indicator).

Berdasarkan atribut kunci ini maka dapat dihitung nilai persepsi dan harapan dari tiap pengguna jasa laboratorium. Skor harapan didapatkan rumus :

$$
\text { Eij } \quad=\frac{\sum_{i=1}^{n j} T E i j}{N j}
$$

Keterangan :

Eij = skor harapan responden pada dimensi $\mathrm{j}$

TEij = skor harapan responden pada atribut pelayanan $\mathrm{i}$

$\mathrm{Nj} \quad$ = jumlah responden

Skor persepsi responden pada dimensi j didapatkan dengan cara :

$$
\mathrm{Pij}=\frac{\sum_{i=1}^{n j} T P \ddot{j}}{N j}
$$

Keterangan :

Pij = skor persepsi responden pada dimensi $\mathrm{j}$

TPij = skor persepsi responden pada atribut pelayanan $\mathrm{i}$

$\mathrm{Nj} \quad=$ jumlah responden

Setelah mendapatkan skor harapn dan persepsi maka dilakukan penghitungan gap dengan rumus :

Keterangan :

$$
\text { Gap }=\text { Pij }- \text { Eij }
$$

$$
\text { Pij }=\text { Skor persepsi }
$$

Eij $=$ Skor harapan

Langkah selanjutnya ialah enentukan target kepuasan yang akan dicapai dalam persen. Setelah mengetahui target yang akan dicapai lalu akan dihitung tingkat kepuasan pelanggan akan kinerja saat ini dengan rumus :

$$
\text { Tingkat kepuasan }=\frac{\text { Pij }}{\text { Eij }} \times 100 \%
$$

Keterangan :

Pij = skor persepsi pada atribut $\mathrm{i}$ dimensi $\mathrm{j}$

Eij $=$ skor harapan pada atribut I dimensi $\mathrm{j}$
Lalu dilakukan penghitungan DPMO (defect per Millions Opportunities) yang didapatkan dengan cara berikut ini:

$$
\text { DPMO }=\left(1-\frac{\text { Skor persepsi }}{\text { Target Kepuasan }}\right) \times 1000000
$$

Keterangan :

$$
\text { DPMO = Defect per Millions Opportunities }
$$

Setelah mendapatkan nilai DPMO maka nilai tersebut akan dikonversi ke dalam nilai sigma.

$$
\text { Nilai sigma }=\operatorname{normsinv}\left(1-\left(\frac{\text { DPMO }}{1000000}\right)\right)+1.5
$$

3. Tahap Analyze

Pada tahap Analyze yaitu menganalisis hubungan sebab akibat berbagai faktor yang mempengaruhi input kunci dan output kunci, sehingga dapat diketahui faktor-faktor dominan yang perlu dikendalikan.

\section{Tahap Improve}

Merupakan fase peningkatan proses dan menghilangkan sebab-sebab cacat untuk meningkatkan kualitas pelayanan. Setelah sumbersumber dan akar permasalahan teridentifikasi makan dilakukan rencana tindakan untuk meningkatkan kualitas Six Sigma.

5. Tahap Control

Pada tahap ini hasil-hasil peningkatan kualitas di dokumentasikan dan disebarluaskan, praktek-praktek terbaik yang sukses dalam meningkatkan proses distandarisasikan dan disebarluaskan, prosedurprosedur didokumentasikan dan dijadikan pedoman kerja standar, serta kepemilikan atau tanggung jawab ditransfer dari Tim Six Sigma kepada pemilik atau penanggungjawab proses yang berarti proyek Six Sigma berakhir pada tahap ini (Gaspersz, 2002).

\subsection{ServQual}

Dalam Tjiptono dan Fandy (2011) dituliskan SERVQUAL (Service Quality) merupakan suatu konsep pengukuran kualitas pelayanan yang dilontarkan oleh Parasuraman et al. (1985) model ini dikembangkan dengan maksud untuk membantu para manager dalam menganalisis sumber masalah kualitas dan memahami cara-cara memperbaiki kualitas jasa.

Model SERVQUAL didasarkan pada asumsi bahwa konsumen membandingkan kinerja jasa pada atribut-atribut relevan dengan standar ideal/sempurna untuk masing-masing atribut jasa. Bila kinerja sesuai atau melebihi standar maka persepsi atau kualitas jasa secara keseluruhan akan positif dan sebaliknya model ini menganalisis gap antara dua variable pokok, yakni jasa yang diharapkan (expected service) dan jasa yang dipersepsikan (perceived service). Metode/model SERVQUAL terdiri dari lima dimensi utama yaitu :

\section{a. Realibility ( Reliabilitas)}

Kemampuan perusahaan untuk memberikan pelayanan sesuai dengan janji yang diberikan kepada konsumen, termasuk didalamnya waktu 
pelayanan yang cepat, pelayanan yang akurat, sikap personel yang simpatik kepada tiap pelanggan.

b. Assurance (Jaminan)

Faktor yang mempengaruhi kepercayaan pelanggan terhadap perusahaan. Assurance terdiri dari beberapa komponen yaitu komunikasi, kredibilitas, keamanan, kompetensi dan sopan santun.

c. Tangibility (Bukti Fisik)

Membahas tentang sarana dan prasarana fisik yang disediakan oleh perusahaan untuk pelanggan. Contohnya ruangan yang representative, peralatan yang lengkap, penampilan karyawan yang baik.

d. Emphaty (Empati)

Berkenaan dengan pengertian dan pengetahuan perusahaan terhadap pelanggannya, memahami kebutuhan tiap pelanggan secara spesifik, memberikan perhatian secara personal pada tiap pelanggan, dan waktu operasional yang memberikan kenyamanan.

e. Responsiveness (Daya Tanggap)

Berhubungan dengan kemauan personel untuk membantu dan memberikan pelayanan yang cepat dan tepat bagi tiap pelanggan yang disertai dengan penyampaian informasi yang jelas.

\subsection{Konsep Dashboard}

Menurut Eckerson (2010), Dashboard kinerja adalah sistem informasi bisnis yang lengkap yang dibangun diatas infrastruktur bisnis intelligent dan data-integrasi. Dashboard kinerja menerjemahkan strategi organisasi ke dalam tujuan, metrik, inisiatif, dan tugas-tugas yang disesuaikan untuk masingmasing kelompok dan individu dalam organisasi. Mereka membantu untuk secara proaktif meningkatkan keputusan dan mengoptimalkan proses.

\subsection{Pengembangan Model PureShare}

Metode pengembangan sistem informasi kinerja layanan laboratorium ini akan didasarkan pada metode PureShare (Pureshare, 2013). Metodologi PureShare memberikan penekanan pada kesesuaian antara tujuan bisnis dengan kebutuhan teknologi organisasi (Gambar 1). Perancangan sistem dilakukan dengan pendekatan top-down dan bottomup (Haryanti,2008).

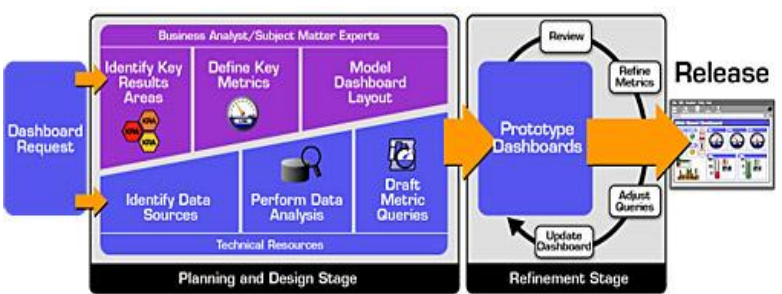

Gambar 1. Metode PureShare (PureShare.com)
Tahapan yang ada pada metode ini yaitu :

a. Perencanaan dan desain

Desain bersifat top down yang berfokus pada bisnis dan pengguna akhir. Menetapkan bidang fokus utama untuk pengguna serta indikator kinerja. Menetapkan fitur-fitur utama yang akan dimasukkan ke dalam dashboard.

b. Review Sistem dan data

Dilakukan bersamaan dengan tahap perencanaan dan desain. Menentukan data apa yang tersedia, bagaimana mengaksesnya, menilai kualitas, dan mengembangkan metrik. Menganalisa data untuk lebih memahami sumber data dan mengembangkan rekomendasi.

c. Perancangan prototipe

Pembuatan prototipe antar muka untuk memberikan pandangan singkat dari hasil akhir yang didapatkan. Pada tahap ini pengguna terlibat untuk memberikan umpan balik dan saran untuk implementasi.

d. Perbaikan prototype

Melakukan serangkaian ulasan prototype. Mengumpulkan umpan balik dan membuat penyesuaian yang diperlukan. Memastikan bahwa informasi yang digunakan tepat dan data yang ada akurat. Menentukan ambang batas yang tepat dan target.

e. Release

Memperkenalkan metrik kepada pengguna. Melatih pengguna sehingga dapat dengan mudah menggunakan metrik dan menilai informasi yang disampaikan.

f. Perbaikan terus menerus

Metodologi ini memfasilitasi siklus perbaikan secara terus menerus.

\section{Metodologi}

\subsection{Bahan dan Alat Penelitian}

Data yang digunakan yaitu data primer kuesioner kepuasan pelanggan serta data sekunder indikator berdasarkan Permenkes no. 129/Menkes/SK/2008.

Kuesioner yang digunakan mengacu pada ServQual Parasuraman et al. (1985) Atribut pertanyaan dapat dilihat pada tabel berikut ini :

Pada Tabel 2 berikut ini dapat dilihat daftar pertanyaan untuk dimensi reliabilitas untuk mengukur kepuasan pelanggan . 
Tabel 2. Pertanyaan untuk dimensi reliabilitas

\begin{tabular}{|c|c|c|c|}
\hline Harapan & No & Pertanyaan/Atribut & $\begin{array}{l}\text { Kinerja/ } \\
\text { Persepsi }\end{array}$ \\
\hline & 2 & $\begin{array}{l}\text { Menyediakan jasa sesuai } \\
\text { yang dijanjikan. } \\
\text { Dapat diandalkan dalam } \\
\text { menangani masalah jasa } \\
\text { pelanggan. } \\
\text { Menyampaikan jasa } \\
\text { secara benar semenjak } \\
\text { pertama kali }\end{array}$ & \\
\hline & 6 & $\begin{array}{l}\text { Menyampaikan jasa } \\
\text { sesuai waktu yang } \\
\text { dijanjikan } \\
\text { Menyimpan } \\
\text { catatan/dokumen tanpa } \\
\text { kesalahan. } \\
\text { Waktu tunggu hasil } \leq 140 \\
\text { menit manual }\end{array}$ & \\
\hline
\end{tabular}

Daftar pertanyaan/atribut untuk dimensi daya tanggap dapat dilihat pada Tabel 3.

Tabel 3. Pertanyaan untuk dimensi daya tanggap

\begin{tabular}{|c|c|c|c|}
\hline Harapan & No & Pertanyaan/Atribut & Kinerja/Persepsi \\
\hline & $\begin{array}{l}8 \\
9\end{array}$ & $\begin{array}{l}\text { Menginformasikan } \\
\text { pelanggan tentang } \\
\text { kepastian waktu } \\
\text { penyampaian jasa. } \\
\text { Layanan yang } \\
\text { segera/cepat bagi } \\
\text { pelanggan } \\
\text { Kesediaan untuk } \\
\text { membantu } \\
\text { pelanggan } \\
\text { Kesiapan untuk } \\
\text { merespon } \\
\text { permintaan } \\
\text { pelanggan. }\end{array}$ & \\
\hline
\end{tabular}

Tabel 4 berikut ini menunjukkan pertanyaan atau atribut pada dimensi jaminan.

Tabel 4. Pertanyaan untuk dimensi jaminan

\begin{tabular}{|c|c|c|c|}
\hline Harapan & No & Pertanyaan/Atribut & Kinerja/Persepsi \\
\hline & 14 & $\begin{array}{l}\text { Karyawan yang } \\
\text { menumbuhkan rasa } \\
\text { percaya para } \\
\text { pelanggan. } \\
\text { Membuat pelanggan } \\
\text { merasa aman } \\
\text { sewaktu melakukan } \\
\text { transaksi. } \\
\text { Karyawan yang } \\
\text { secara konsisten } \\
\text { bersikap sopan } \\
\text { Karyawan yang } \\
\text { mampu menjawab } \\
\text { pertanyaan } \\
\text { pelanggan. } \\
\text { Ketepatan hasil } \\
\text { pemeriksaan }\end{array}$ & \\
\hline
\end{tabular}

Pada Tabel 5 terdapat pertanyaan/atribut untuk mengukur kepuasan pelanggan pada dimensi empati

Tabel 5. Pertanyaan untuk dimensi empati

\begin{tabular}{rrl}
\hline Harapan & No & Pertanyaan/Atribut \\
\hline 16 & $\begin{array}{l}\text { Memberikan perhatian } \\
\text { individual kepada para } \\
\text { pelanggan. }\end{array}$ \\
\hline 17 & $\begin{array}{l}\text { Karyawan yang } \\
\text { memperlakukan } \\
\text { pelanggan secara penuh } \\
\text { perhatian. }\end{array}$ \\
18 & $\begin{array}{l}\text { Sungguh-sungguh } \\
\text { mengutamakan } \\
\text { kepentingan pelanggan. }\end{array}$ \\
19 & $\begin{array}{l}\text { Karyawan yang } \\
\text { memahami kebutuhan } \\
\text { pelanggan. }\end{array}$ \\
20 & $\begin{array}{l}\text { Waktu beroperasi (jam } \\
\text { kantor) yang nyaman. }\end{array}$ \\
\hline
\end{tabular}

Pada Tabel 6 berikut ini dapat dilihat daftar pertanyaan untuk mengukur kepuasan pelanggan pada dimensi bukti fisik

Tabel 6. Pertanyaan untuk dimensi bukti fisik

\begin{tabular}{|c|c|c|c|}
\hline Harapan & No & Pertanyaan/Atribut & Kinerja/Persepsi \\
\hline & $\begin{array}{l}21 \\
22 \\
23\end{array}$ & $\begin{array}{l}\text { Peralatan modern } \\
\text { Fasilitas yang } \\
\text { berdaya tarik visual } \\
\text { Karyawan yang } \\
\text { berpenampilan rapi } \\
\text { dan professional } \\
\text { Materi-materi } \\
\text { berkaitan dengan } \\
\text { jasa yang berdaya } \\
\text { tarik visual } \\
\text { Laboratorium } \\
\text { memiliki peralatan } \\
\text { medis yang cukup } \\
\text { lengkap }\end{array}$ & \\
\hline
\end{tabular}

\subsection{Prosedur Penelitian}

Metode penelitian ini mengambil model pada metode yang dikembangkan oleh PureShare. Tahapan dari penelitian ini dapat dilihat pada diagram alir Gambar 2 berikut ini : 


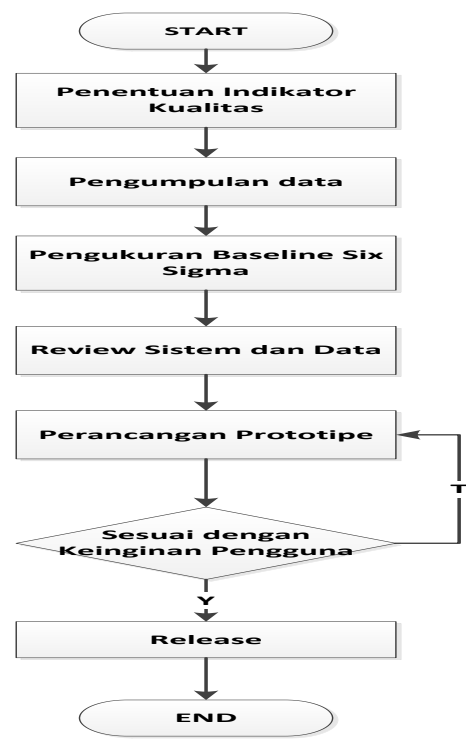

Gambar 2. Alur Penelitian

\subsection{Perancangan Sistem}

Merupakan suatu diagram yang digunakan untuk memodelkan proses bisnis yang ada di dalam sistem. Use Case Diagram dari sistem informasi kinerja layanan laboratorium dapat dilihat pada Gambar 3.

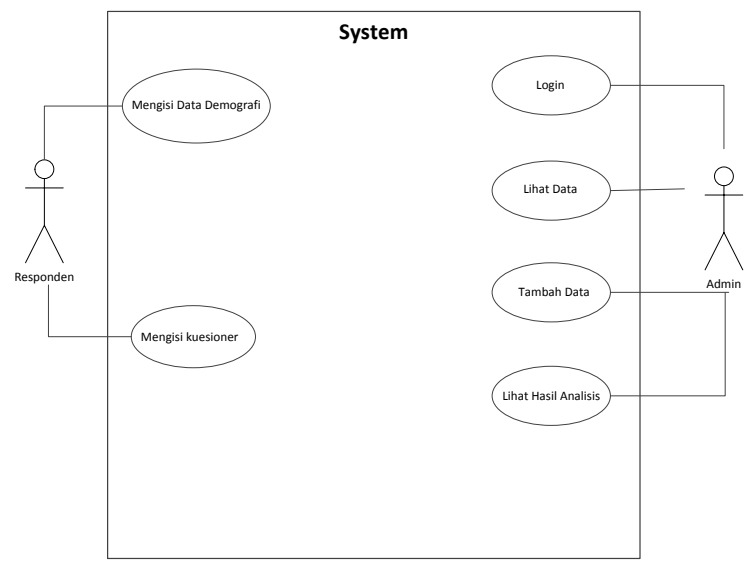

Gambar 3. Use Case sistem

Activity diagram adalah representasi grafis dari seluruh tahapan alur kerja. Diagram ini mengandung aktivitas, pilihan tindakan, perulangan dan hasil dari aktivitas tersebut. Pada pemodelan UML, diagram ini dapat digunakan untuk menjelaskan proses bisnis dan alur kerja operasional secara langkah demi langkah dari komponen suatu sistem. Aktifitas yang terjadi pada sistem informasi kinerja layanan laboratorium dapat dilihat pada Gambar 4.

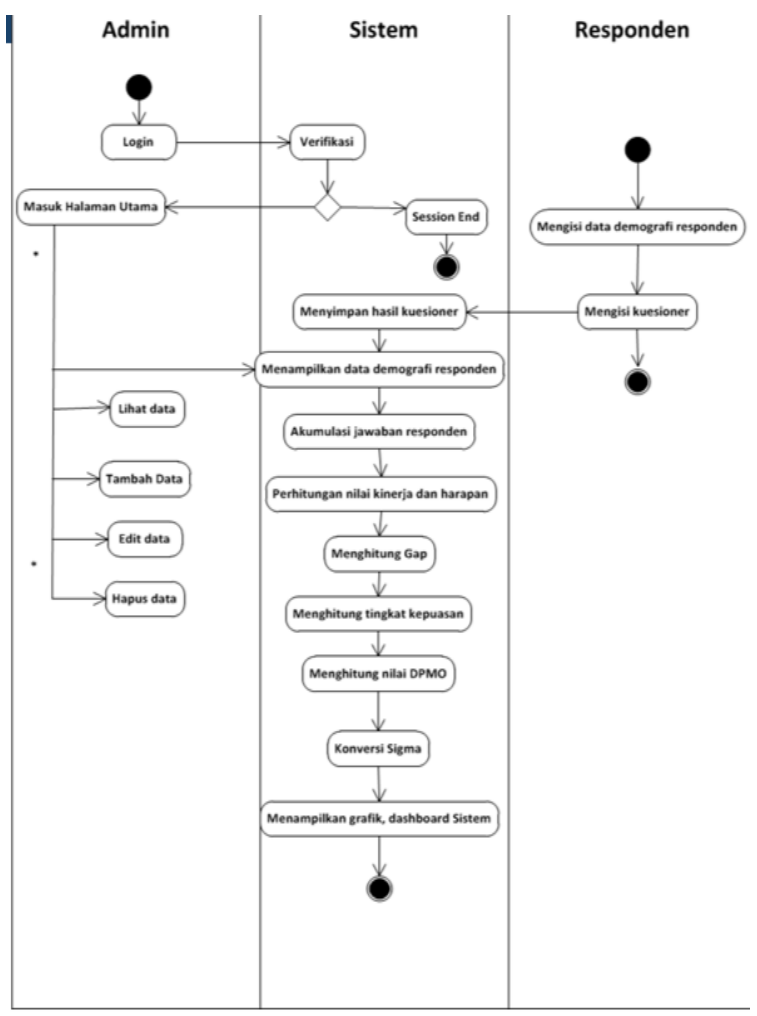

Gambar 4. Diagram aktivitas

\section{Hasil dan Pembahasan}

\subsection{Hasil Penelitian}

Hasil penelitian ini yaitu suatu sistem informasi kinerja layanan laboratorium yang berbasis web yang menggabungkan metode Servqual dan Six Sigma. Sistem ini menggunakan survey kepuasan pelanggan untuk melihat sejauh mana gap antara kinerja laboratorium saat ini dan harapan pelanggan akan kinerja di masa yang akan datang, dan menentukan tingkat sigma yang dicapai oleh layanan laboratorium saat ini.

Informasi yang ditampilkan berupa hasil pengukuran kinerja yang telah dicapai berdasarkan empat indikator yang telah ditentukan yaitu waktu tunggu hasil pelayanan laboratorium, pelaksana ekspertisi hasil pemeriksaan laboratorium, tidak adanya kesalahan penyerahan hasil pemeriksaan laboratorium kepuasan pelanggan yang bersumber dari survey kepuasan pelanggan dengan menggunakan metode Six Sigma.

Kerangka sistem informasi kinerja layanan laboratorium yang dihasilkan Gambar 5. 


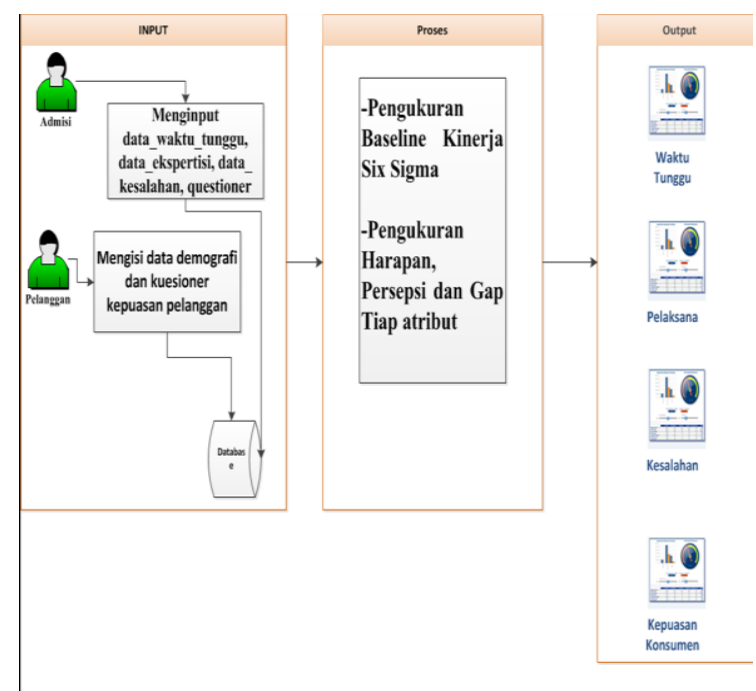

Gambar 5. Kerangka sistem informasi

Dari gambar diatas dapat dijelaskan bahwa sistem informasi kinerja layanan laboratorium ini merupakan suatu sistem informasi berbasis web yang menggunakan bahasa pemrograman PHP dan MySQL sebagai server database yang menyajikan kinerja pelayananan laboratorium berdasarkan indikator yang telah ditentukan terlebih dahulu dalam bentuk panel atau dashboard.

Hasil dari pengukuran kinerja dapat dilihat pada Gambar 6.

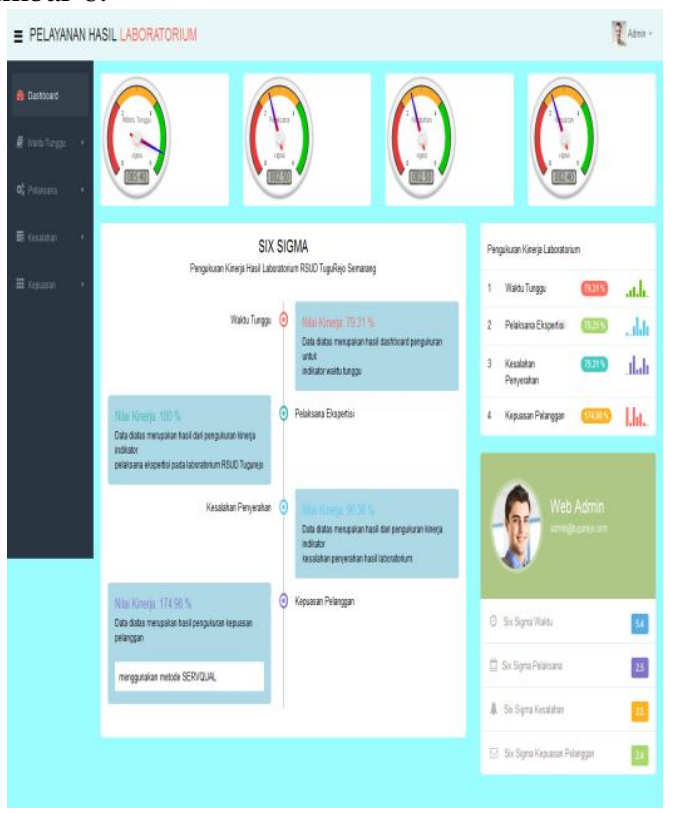

Gambar 6. Halaman utama kinerja layanan

Gambar 6 diatas merupakan halaman utama sistem informasi kinerja layanan dimana dapat dilihat nilai kepuasan untuk keseluruhan indikator, serta nilai sigma yang dicapai. Sedangkan Gambar 7 dibawah ini merupakan hasil perhitungan nilai persepsi, harapan, gap yang timbul, target yang ingin dicapai, tingkat kepuasan, nilai DPMO serta nilai sigma.

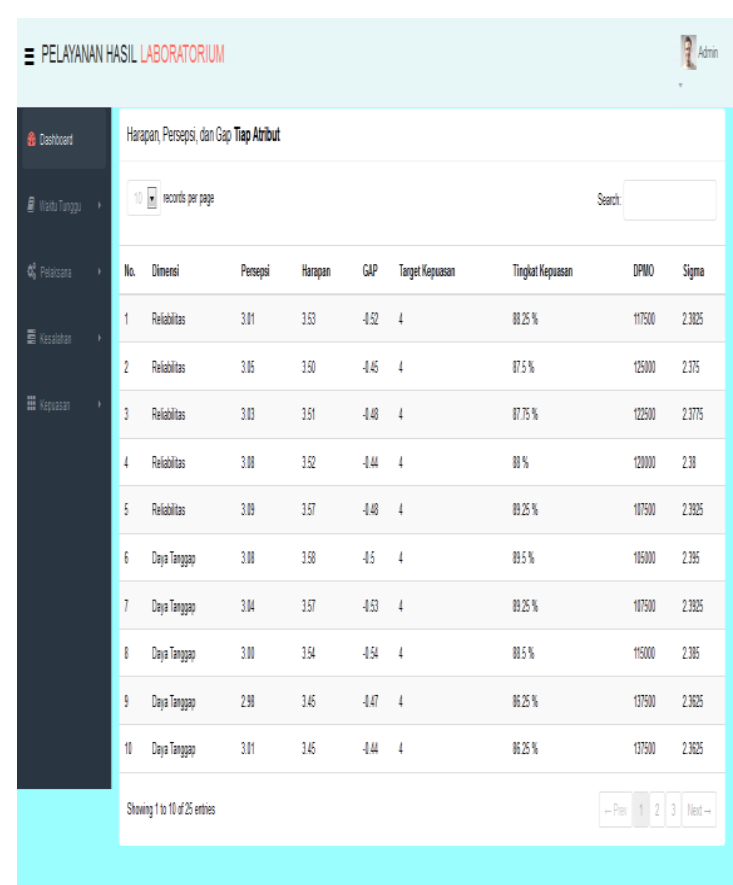

Gambar 7. Halaman sigma untuk tiap atribut

\subsection{Pembahasan}

\subsubsection{Tahap Define}

Pada tahap ini yaitu menetapkan masalah dan target dari Six Sigma. Yang menjadi target ialah bagaimana meningkatkan kinerja pelayanan agar dapat memenuhi keinginan atau harapan pengguna jasa laboratorium RSUD Tuguredjo Semarang. Sebagai salah satu faktor yang mempengaruhi mutu pelayanan rumah sakit, maka laboratorium yang memiliki kinerja yang baik dapat dilihat dari bagaimana pelayanan yang diberikan pegawai pada pasien, tidak adanya kesalahan dalam pengambilan/penyediaan sampel, pengolahan sampel, ketepatan waktu dalam penyampaian hasil pemeriksaan. Untuk mencapai target ini maka dibutuhkan pendefinisian atribut kunci yang akan dijadikan atribut pertanyaan Servqual. Atribut ini dapat dilihat pada Tabel 7 .

\subsubsection{Tahap Measure}

Pada tahap ini dilakukan pengukuran baseline kinerja pada tingkat atribut. Data yang digunakan pada perhitungan ini didapat dari survey yang dilakukan kepada 100 responden yang mewakili pengguna jasa laboratorium RSUD Tuguredjo Semarang, atribut pertanyaan merupakan pengembangan model Servqual milik Parasuraman, et al. (1985) Perhitungan nilai DPMO dan level sigma untuk tiap atribut.

Yang pertama dilakukan pada tahap ini yaitu menentukan CTQ (Critical to Quality). Atribut kunci kepuasan pelanggan untuk peningkatan kinerja layanan laboratorium medis ditentukan berdasarkan kerangka SERVQUAL dari Parasuraman et al. 
(1985) yang dikembangkan sesuai kebutuhan pada Tabel 7.

Tabel 7. Tabel critical to quality

\begin{tabular}{|c|c|c|}
\hline $\begin{array}{l}\text { No } \\
\text { Atribut }\end{array}$ & Dimensi & Atribut Pertanyaan \\
\hline 1 & $\mathrm{R} 1$ & $\begin{array}{l}\text { Menyediakan jasa sesuai yang } \\
\text { dijanjikan. }\end{array}$ \\
\hline 2 & $\mathrm{R} 2$ & $\begin{array}{l}\text { Dapat diandalkan dalam } \\
\text { menangani masalah jasa } \\
\text { pelanggan }\end{array}$ \\
\hline 3 & R3 & $\begin{array}{l}\text { Menyampaikan jasa secara benar } \\
\text { semenjak pertama kali }\end{array}$ \\
\hline 4 & $\mathrm{R} 4$ & $\begin{array}{l}\text { Menyampaikan jasa sesuai waktu } \\
\text { yang dijanjikan }\end{array}$ \\
\hline 5 & $\mathrm{R} 5$ & $\begin{array}{l}\text { Menyimpan catatan/dokumen } \\
\text { tanpa kesalahan }\end{array}$ \\
\hline 6 & D1 & $\begin{array}{l}\text { Waktu tunggu hasil } \leq 140 \text { menit } \\
\text { manual }\end{array}$ \\
\hline 7 & D2 & $\begin{array}{l}\text { Menginformasikan pelanggan } \\
\text { tentang kepastian waktu } \\
\text { penyampaian jasa }\end{array}$ \\
\hline 8 & D3 & $\begin{array}{l}\text { Layanan yang segera/cepat bagi } \\
\text { pelanggan }\end{array}$ \\
\hline 9 & D4 & $\begin{array}{l}\text { Kesediaan untuk membantu } \\
\text { pelanggan }\end{array}$ \\
\hline 10 & D5 & $\begin{array}{l}\text { Kesiapan untuk merespon } \\
\text { permintaan pelanggan }\end{array}$ \\
\hline 11 & $\mathrm{~J} 1$ & $\begin{array}{l}\text { Karyawan yang menumbuhkan } \\
\text { rasa percaya para pelanggan }\end{array}$ \\
\hline 12 & $\mathrm{~J} 2$ & $\begin{array}{l}\text { Membuat pelanggan merasa aman } \\
\text { sewaktu melakukan transaksi }\end{array}$ \\
\hline 13 & $\mathrm{~J} 3$ & $\begin{array}{l}\text { Karyawan yang secara konsisten } \\
\text { bersikap sopan }\end{array}$ \\
\hline 14 & $\mathrm{~J} 4$ & $\begin{array}{l}\text { Karyawan yang mampu } \\
\text { menjawab pertanyaan pelanggan. }\end{array}$ \\
\hline 15 & $\mathrm{~J} 5$ & Ketepatan hasil pemeriksaan \\
\hline 16 & E1 & $\begin{array}{l}\text { Memberikan perhatian individual } \\
\text { kepada para pelanggan. }\end{array}$ \\
\hline 17 & E2 & $\begin{array}{l}\text { Karyawan yang memperlakukan } \\
\text { pelanggan secara penuh perhatian }\end{array}$ \\
\hline 18 & E3 & $\begin{array}{l}\text { Sungguh-sungguh mengutamakan } \\
\text { kepentingan pelanggan. }\end{array}$ \\
\hline 19 & E4 & $\begin{array}{l}\text { Karyawan yang memahami } \\
\text { kebutuhan pelanggan. }\end{array}$ \\
\hline 20 & E5 & $\begin{array}{l}\text { Waktu beroperasi (jam kantor) } \\
\text { yang nyaman. }\end{array}$ \\
\hline 21 & B1 & Peralatan modern \\
\hline 22 & B2 & Fasilitas yang berdaya tarik visual \\
\hline 23 & B3 & $\begin{array}{l}\text { Karyawan yang berpenampilan } \\
\text { rapi dan professional }\end{array}$ \\
\hline 24 & B4 & $\begin{array}{l}\text { Materi-materi berkaitan dengan } \\
\text { jasa yang berdaya tarik visual }\end{array}$ \\
\hline 25 & B5 & $\begin{array}{l}\text { Laboratorium memiliki peralatan } \\
\text { medis yang cukup lengkap }\end{array}$ \\
\hline
\end{tabular}

Setelah menentukan atribut kunci maka dilakukan pengukuran tingkat kepuasan pelanggan akan kinerja laboratorium saat ini. Pengukuran tingkat kepuasan saat ini diperoleh dengan rumus :

$$
\text { Tingkat kepuasan }=\frac{\mathrm{Pij}_{\mathrm{ij}}}{\mathrm{Eij}} \times 100 \%
$$

Keterangan :

Pij = skor persepsi pada atribut $\mathrm{i}$ dimensi $\mathrm{j}$

$\mathrm{Eij}=$ skor harapan pada atribut $\mathrm{i}$ dimensi $\mathrm{j}$

Sebagai contoh kita ambil atribut pertanyaan 1 pada dimensi realibilitas maka didapat tingkat kepuasan saat ini yaitu :

$$
\begin{aligned}
\text { Tingkat kepuasan }= & \frac{2.93}{3.43} \times 100 \% \\
& =85.42 \%
\end{aligned}
$$

Setelah mendapatkan tingkat kepuasan pelanggan untuk akan kinerja saat ini, lalu dilakukukan pengukuran DPMO (Defect per Million Opportunities). Nilai DPMO diperoleh dengan rumus :

$$
\text { DPMO }=\left(1-\frac{\text { Skor persepsi }}{\text { Target Kepuasan }}\right) \times 1000000
$$

Keterangan :

DPMO = defect per Millions Opportunities

Sebagai contoh kita ambil pada atribut pertanyaan 1 pada dimensi realibilitas, diperoleh hasil DPMO sebagai berikut :

$$
\begin{aligned}
\text { DPMO } & =\left(1-\frac{2.93}{5}\right) \times 1.000 .000 \\
& =414.000
\end{aligned}
$$

Artinya dalam sjuta kesempatan yang ada terdapat 402.500 kemungkinan kegagalan di dalam memenuhi kebutuhan pelanggan.

Setelah mendapatkan nilai DPMO, maka nilai tersebut akan dikonversi kedalam sigma. Konversi nilai sigma diperoleh berdasarkan rumus :

Nilai sigma $=\operatorname{normsinv}\left(1-\left(\frac{\text { DPMO }}{1000000}\right)\right)+1.5$

Sebagai keterangan, angka 1.000 .000 disini merupakan angka kemungkinan terjadinya kegagalan dalam Six Sigma (nilai kegagalan dalam Six Sigma dihitung berdasarkan per 1.000 .000 kejadian). Sedangkan angka 1.5 merupakan konstan sesuai dengan konsep Motorola yang mengizinkan terjadinya pergeseran pada nilai rata-rata sebesar \pm 1.5 sigma (Wisnubroto,Anggoro, 2012).

Contoh jika kita mengambil atribut pertanyaan 1 pada dimensi reliabilitas maka nilai sigma yang didapatkan adalah :

$$
\begin{aligned}
\text { Nilai sigma } & =\operatorname{normsinv}\left(1-\left(\frac{414000}{1000000}\right)\right)+1.5 \\
& =2.086
\end{aligned}
$$

Hasil pengukuran untuk semua atribut pada tingkat outcomes dapat dilihat pada Gambar 8. 


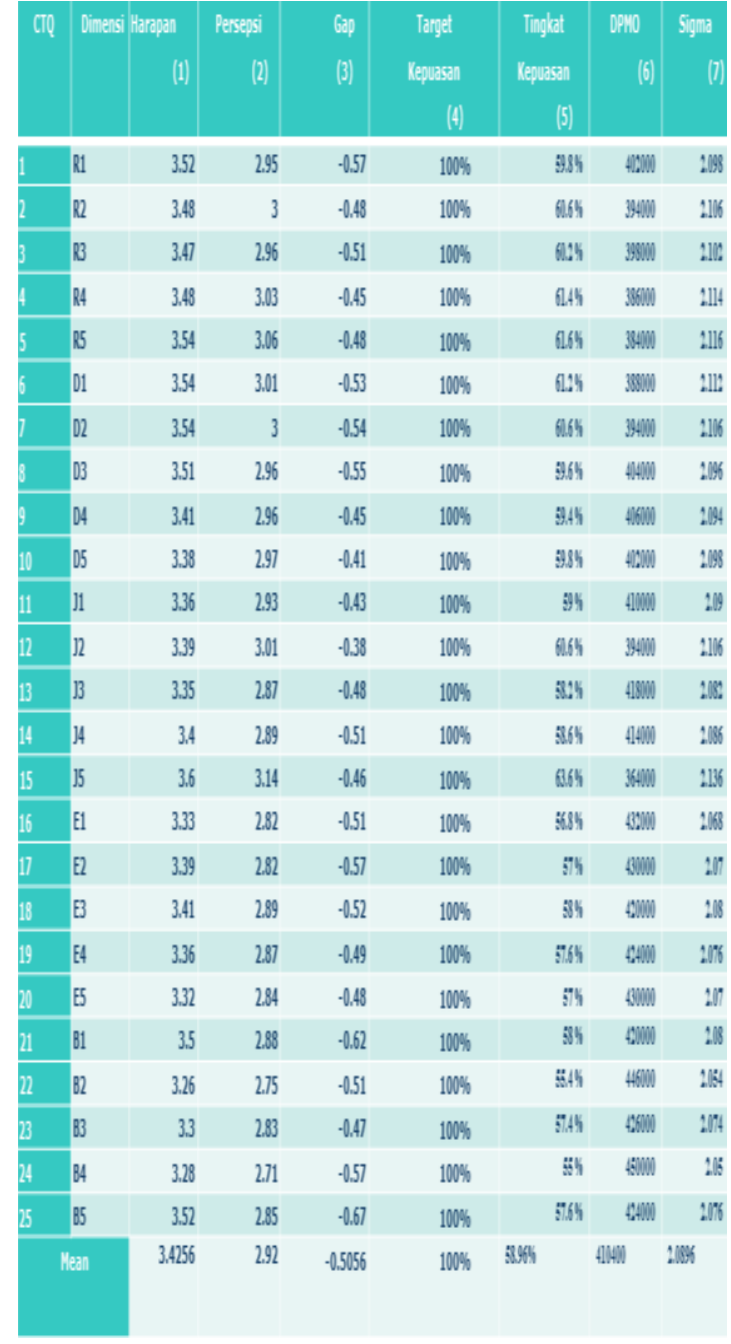

Gambar 8. Nilai atribut untuk tingkat outcomes

Dari hasil pengukuran dapat diketahui bahwa nilai rata-rata dari persepsi konsumen terhdap kinerja saat ini yaitu 2.98, harapan konsumen terhadap kinerja 3.4508, gap antara persepsi dan harapan konsumen yaitu -0.5028 , kepuasan pelanggan akan kinerja saat ini 58.96\%, nilai DPMO 410400, dan niali sigma ada pada tingkat 2.0896 .

\subsubsection{Tahap Analyze}

Pada tahap ini yaitu menganalisis hubungan sebab akibat berbagai faktor yang dipelajari untuk mengetahui faktor-faktor dominan yang perlu dikendalikan (Gasperz dan Fontana, 2011). Cara yang dapat dilakukan antara lain :

a. Menentukan kapabilitas proses kinerja layanan pada RSUD Tuguredjo

Berdasarkan pengukuran baseline kinerja pada tingkat outcome untuk tiap atribut maka didapatkan kapabilitas proses kinerja pelayanan laboratorium RSUD Tuguredjo tertara pada Tabel 9.
Tabel 9. Tabel kapabilitas proses kinerja layanan laboratorium

\begin{tabular}{|c|c|c|c|c|}
\hline Atribut & $\begin{array}{l}\text { Tingkat } \\
\text { DPMO }\end{array}$ & $\begin{array}{l}\text { Tingkat } \\
\text { Kepuasan }\end{array}$ & $\begin{array}{l}\text { Target } \\
\text { Kepuasan }\end{array}$ & $\begin{array}{l}\text { Deskripsi } \\
\text { Kesalahan } \\
\text { Potensial }\end{array}$ \\
\hline R1 & 414000 & $85.42 \%$ & $100 \%$ & $\begin{array}{l}\text { Menyedia } \\
\text { kan jasa } \\
\text { sesuai } \\
\text { yang } \\
\text { dijanjikan. }\end{array}$ \\
\hline D3 & 416000 & $84.88 \%$ & $100 \%$ & $\begin{array}{l}\text { Layanan } \\
\text { yang } \\
\text { segera/cep } \\
\text { at bagi } \\
\text { pelanggan }\end{array}$ \\
\hline $\mathrm{J} 3$ & 432000 & $85.8 \%$ & $100 \%$ & $\begin{array}{l}\text { Karyawan } \\
\text { yang } \\
\text { secara } \\
\text { konsisten } \\
\text { bersikap } \\
\text { sopan }\end{array}$ \\
\hline E2 & 442000 & $83.53 \%$ & $100 \%$ & $\begin{array}{l}\text { Karyawan } \\
\text { yang } \\
\text { memperla } \\
\text { kukan } \\
\text { pelanggan } \\
\text { secara } \\
\text { penuh } \\
\text { perhatian. }\end{array}$ \\
\hline B4 & 462000 & $82.77 \%$ & $100 \%$ & $\begin{array}{l}\text { Fasilitas } \\
\text { yang } \\
\text { berdaya } \\
\text { tarik } \\
\text { visual }\end{array}$ \\
\hline
\end{tabular}

b. Mengidentifikasi faktor-faktor yang dominan dan akar penyebabnya

Dari tabel diatas dapat dilihat bahwa faktor yang dominan adalah faktor sumber daya manusia yang terbatas hingga terkadang tidak maksimal didalam melayani pelanggan, selain itu adalah ruangan tunggu yang dirasa gelap dan suram sehingga membuat pelanggan merasa tidak nyaman.

\subsubsection{Tahap Improve}

Pada saat ini adalah menetapkan rencana perbaikan untuk menurunkan tingkat defect yang tinggi pada variable-variabel yang telah ditentukan. Rencana ini hendakanya mencakup identifikasi alternative prioritas yang harus diperbaiki. Usulan rencana perbaikan yang dapat dilankukan adalah melakukan training terhadap karyawan tentang bagaiman seharusnya bersikap kepada pelanggan, menyediakan ruang tunggu dan ruang periksa yang representative agar pelanggan merasa nyaman, evaluasi kinerja karyawan secara berkala.

\subsubsection{Tahap Control}

Dari hasil tersebut dapat dilihat bahwa kinerja pelayanan yang diberikan oleh laboratotium belum masuk dalam kategori baik. Perlu dilakukan evaluasi 
dan monitoring secara berkelanjutan untuk mencapai hasil kinerja yang optimal.

\section{Kesimpulan dan Saran}

Sistem informasi yang dihasilkan telah dapat melakukan pengukuran kinerja layanan laboratorium saat ini. Hasil dari pengukuran ini berupa nilai persepsi konsumen terhadap kinerja saat ini, nilai harapan konsumen akan kinerja di masa yang akan datang, gap antara persepsi dan harapan pelanggan, kepuasan pelanggan saat ini, nilai DPMO (Defect Per Million Opportunities), serta tingkat sigma yang telah dicapai oleh kinerja layanan laboratorium untuk saat ini.

Dalam pembuatan sistem informasi ini kerangka kuesioner yang merupakan inputan dari sistem dibuat berdasarkan metode Servqual, yang terdiri dari 5 dimensi yaitu reliabilitas, daya tanggap, jaminan, empati dan bukti fisik yang dijabarkan menjadi 25 atribut kunci.

Sistem informasi ini belum mengatur hak akses antara administrator dan pengguna lainnya (penanggung jawab laboratorium, kepala laboratorium). Selain itu sistem ini belum diuji untuk jumlah data yang lebih besar dari 100 sehingga belum diketahui apakah sistem ini berjalan dengan kecepatan yang sama untuk jumlah data yang lebih besar.

Hasil pengukuran kinerja layanan laboratorium dengan menggunakan sistem ini ServQual menunjukkan bahwa hasil yang diperoleh nilai ratarata dari persepsi konsumen terhadap kinerja saat ini yaitu 2.883, harapan konsumen terhadap kinerja 3.3768, gap antara persepsi dan harapan konsumen yaitu -0.4936 , kepuasan pelanggan akan kinerja saat ini 85.37\%, nilai DPMO 423360, dan nilai sigma ada pada tingkat 2.07664., sehingga perlu dilakukan evaluasi untuk memperbaiki kinerja serta memenuhi harapan pelanggan.

Pada sistem informasi ini perlu dilakukan pengaturan hak akses antara administrator dan pengguna lainnya. Selain itu perlu dilakukan uji coba dengan memasukkan data yang lebih banyak untuk melihat kestabilan sistem. Untuk mendapatkan pengukuran kinerja yang lebih akurat perlu dilakukan pengukuran kinerja karyawan secara internal untuk mengetahui kinerja sumber daya manusia yang mereka miliki. Tidak hanya persepsi konsumen terhadap jasa yang diberikan.

\section{Daftar Pustaka}

Coskun, A., Inal, T., Unsal, I., Serteser, M., 2010. Six Sigma as a Quality Management Tool : Evaluation of Performance in Laboratory Medicine, 2010, Intech Open.

Eckerson, W., 2010. Performance Dashboards : Measuring, Monotoring, and Managing Your Business, Wiley Publisher, New Jersey.

Gaspersz, V., 2002. Pedoman Implementasi Program Six Sigma Terintegrasi dengan ISO 9001:2000, MBNQA dan HACCP, Gramedia, Jakarta.

Gasperz, V., Fontana, A., 2011. Lean Six Sigma for Manufacturing and Service Industries, Vinchristo Publication, Bogor.

Hariyanti, E., 2008. Pengembangan metodologi pembangunan information dashboard untuk monitoring kinerja organisasi, 2008, e-Indonesia Initiative 2008 (eII2008), Prosiding Konferensi dan Temu Nasional Teknologi Informasi dan Komunikasi untuk Indonesia.

Helfert and Erich., A, 1996. Technical of Financial Analysis : A Practical Guide to Measuring Business Performance, Mc Graw-Hill.

Nevalainen, D., Berte, L., Kraft, C., Leigh, E., Picaso, L., Morgan, T., 2000. Evaluating Laboratory Performance on Quality Indicators with The Six Sigma Scale, Arch Patrol Lab Med.2000;124:516-519.

Parasuraman, A., Zeithaml, V.,Berry, L.L., 1988. SERVQUAL : A multiple-item scale for measuring consumer perception of service quality. Journal of Retailing, Volume 1, PP 1240.

Pureshare, 2013. Metric Implementation Methodology, Website : http://www.pureshare.com/products/proserve_met hod.html, diakses tanggal 5 maret 2013.

Pzydek, T., 2002. The Six Sigma Handbook, Salemba Empat, Jakarta.

Raisinghani, M., S., Ette, H., Pierce, R., Cannon, G., Daripaly, P., 2005. Six Sigma Concept, Tools and Applications, Industrial Management and Data Systems Vol. 105 No.4 PP 491-505.

Rivai, V., Fawzi, A., 2005. Performance Appraisal, Rajagrafindo Persada, Jakarta.

Tjiptono, F., Chandra, G., 2007. Service, Quality and Satisfaction, Andi, Yogyakarta.

Wisnubroto, P., Anggoro, T., 2012. Analisis kualitas pelayanan jasa dengan metode six sigma pada Hotel Malioboro inn yogyakarta, Prosiding Seminar Nasional Aplikasi Sains \& Teknologi (SNAST) Periode III. 